\title{
A Framework for Assessing the Condition of Crowds Exposed to a Fire Hazard Using a Probabilistic Model
}

\author{
Jaziar Radianti and Ole-Christoffer Granmo
}

\begin{abstract}
Allocating limited resources in an optimal manner when rescuing victims from a hazard is a complex and error prone task, because the involved hazards are typically evolving over time; stagnating, building up or diminishing. Typical error sources are: miscalculation of resource availability and the victims' condition. Thus, there is a need for decision support when it comes to rapidly predicting where the human fatalities are likely to occur to ensure timely rescue.

This paper proposes a probabilistic model for tracking the condition of victims when exposed to fire hazards, using a Bayesian Network. The model is extracted from safety literature on human physiological and psychological responses against heat, thermal radiation and smoke. We simulate the state of victims under different fire scenarios and observe the likelihood of fatalities due to fire exposure. We show how our probabilistic approach can serve as the basis for improved decision support, providing real-time hazard and health assessments to the decision makers.
\end{abstract}

Index Terms-Bayesian networks, diagnostic model, emergency evacuation, human response in fire.

\section{INTRODUCTION}

Human fatalities in fire disasters are undesirable, but over the years, they are inevitable [1]. Fire ranks second in maritime casualties after stranding and grounding [2]. In the wake of a maritime fire disaster, emergency decision makers who usually are familiar with the environment can play a decisive role in framing the efficient evacuation. However, uncertainty in a crisis situation can at times be a reason for them to downplay a disaster, or provide affected people with excessively optimistic accounts of the severity of an event.

Safety theory suggests active faults (e.g. committed by e.g. operators) and latent faults as the explanation of major disasters. Latent faults can be hidden defects in a design product, or can be the attitudes, safety culture and the decisions taken at different levels of the organization and with external stakeholders. Latent defects have played a key role in well-known accidents at sea, and the confidence about improved regulations and maritime technology led to lack of awareness of intertwined factors and component in socio-technical systems [3]. When it comes to risk taking and prioritization of issues relating to operational safety, the attitudes of management have changed less. While the influence of management in maritime accidents has been addressed by the International Safety Management (ISM)

Manuscript received July 5, 2013; revised December 3, 2013. This work was supported in part by the Aust-Agder Utvikling- og Kompetansefond (AAUKF), Norway.

Jaziar Radianti and Ole-Christoffer Granmo are with Center of Emergency Management (CIEM), Dept. of Information and Communication Technology, Faculty of Engineering and Science, University of Agder, Grimstad, Norway (e-mail: jaziar.radianti@uia.no,ole.granmo@uia.no)
Code (IMO 1993), specific human factors are still not sufficiently considered [3].

Yet, it is not the intention of this paper to scrutinize the cause of maritime disasters, if they are active or latent faults. The purpose is rather to suggest the probabilistic thinking approach using Bayesian Network (BN) to improve the capability of decision makers to rank priority response and resources in an uncertain event such as a maritime fire disaster. It takes the human behaviors and likelihood of the hazard development, severity of hazard to health of victims in close proximity to the affected area who may face threats from fire effects such as smoke, gas, thermal radiation and temperature into consideration.

The probabilistic approach serves as a basis for future development of smartphone-based decision support by exploiting sensors in the device. The advanced embedded sensors shift the devices into platforms for collecting large-scale data-sets. The signals from sensor devices have been exploited for monitoring health, sport experiences, as well as revealing individual behaviors, activities and context. This approach is intended to build a framework that hopefully can reduce uncertainties and enhance preparedness of organizational emergency response, and the ability of the decision makers to accurately appraise the threats and adopt effective coping strategies.

The contributions of this work lie in the following three areas: 1) Building an intertwined psychological and physiological probabilistic model of a fire disaster; 2) Applying diagnostic thinking for assessing the cause of probability of human health condition; 3) Revealing possible future application of the human health probabilistic model for a mobile-based decision support.

This paper is organized into six sections. Following the introduction is the overview of the relevant studies used as a basis for model building. Section III describes the Bayesian Network approach used in this paper. Section IV presents the probabilistic model of human health and condition in fire hazard. Section $\mathrm{V}$ presents simulations, analysis, and implication for the crisis managers. The conclusion summarizes the ideas and findings in this paper, and reveals future directions of this work.

\section{OVERVIEW OF RELEVANT STUDIES}

Fire safety literature has extensively covered the psychological and physiological effects and human response in fire hazards, and interactions between psychological and physiological effects are likely as indicated by Jin's experiment [4]. Victims suffer both effects from fire and smoke, i.e., rapid drop of visual sharpness and emotional instability, and thus decrease the thinking ability. Jin's study also shows that the victims are more psychologically affected, 
such as being afraid of what was going to happen next, than they were physiologically unable to withstand the smoke. Nevertheless, study on the interactions of psychological and physiological effects on human behavior in fire is scarce. Yet, none uses the probabilistic approach for emergency management decision support, as proposed in this work.

In this paper, psychological effects are defined as the state of the mind of the victim that results in a variety of behavioral responses, performance and decisions. These are distinct from physiological effects which stress more on body functions. Thus, physiological effects are the effects of physical fire parameters such as thermal radiation, heat, toxic gases, and smoke on the human body, as opposed to parameters affecting the mind. For instance, a physiological effect of smoke is that it obscures vision, which may have a psychological effect on the tendency of a victim to enter or avoid a smoke-filled corridor. This review part provides an overview of important psychological and physiological effects that have been studied in the literature.

\section{A. The Behavioral Response}

Numerous studies investigate the psychological factors that are critical for survival in fire [5]-[7]. The ability to fulfill standard evacuation time given different physiological and psychological reasons, has been scrutinized [8]. They reveal how people respond in a fire hazard, which can be divided into three phases.

In the perception phase, the victims receive external cues from the environment such as hearing announcements, or noticing visual signs such as flames, smoke, heat, or debris. It is a recognition process and an awareness of a danger. The fire cues frequently are ambiguous and people who have limited fire knowledge, or have prior fire incidents can easily perceive that a threatening fire is present [7].

In the fire cues validation and definition phase, the victim tries to interpret the consistency of received cues with what can be defined as serious fire, and interpret the risk to themselves or to others. It is a validation of, and response to, danger indicators and a behavioral process that involves victims making decisions on what action to take based on their perceived risk. Stress are likely to develop in this stage.

Bryan [7] who compiles victims' behaviors in fire disasters finds that not all follow the evacuation plan; they may try re-entry, fire-fighting, moving through the smoke or turning back. Non-adaptive behaviors are also apparent. It can be people fleeing the fire incident without regards for others, and inflicting injuries on themselves or others; it can be omission, such as forgetting to close the door; or it can be panic. Note that some researchers argue that panic, competitive flight for exit type of behavior is not supported in the research [9]. The behavior is rather the presence of anxiety due to an unanticipated hazardous event, but the effect can impair the ability to judge the danger.

In the movement phase the action is taken and victims refuge in a safe place. However, the correct action is often influenced by the psychological and physiological responses. Individuals tend to become less selective in the risks involved in the behavioral response. Victims can be overwhelmed by the stress generation and abandon the attempt to formulate a response strategy. This situation can lead into a complete physical immobility [7].
There are more complex processes affecting the human response performance in fire, such as perceptual or judgment ability, and tendency to panic or deny risks. It can be demographic factors, e.g. gender, age, disabilities, and health status, or social characteristics such as travelling with family or in a group. Other factors such as knowledge about fire, ship layout; situation and location (inside or outside room, awake or asleep, standing or lying on bed), and environmental factors (e.g. compartments, size of building, crowd density, easy of way-finding), all add to these complex processes.

\section{B. The Physiological Response}

Human are indeed also susceptible to harmful physical consequences of fire. There are abundant studies on the human physiological response in fire, and the results have been adopted in the fire safety guidelines [10], [11], and handbook [12]. The literature discusses fatality effects due to the exposure from fire parameters such as thermal radiation, heat, smoke, toxic gas.

\section{1) Temperature exposure effects}

Physiological effects on humans in extreme heat conditions originate from three sources, i.e., heat stroke (hyperthermia), body surface burn, and respiratory tract burn [12]. The high air temperature cause gradual increase of body temperature, breathing problems, high pulse, and collapse which can lead into incapacitation. Purser [12] documents an experiment on human performance when exposed to the hot air, as shown in Table I:

\begin{tabular}{|c|c|c|}
\hline Temp $^{\circ} \mathrm{C}$ & Time (Min) & Note \\
\hline 110 & 25 & \\
\hline 180 & 3 & \\
\hline 205 & 4 & Bare headed, protected \\
\hline 126 & 7 & \\
\hline
\end{tabular}

In dry air, when the temperature reaches $120^{\circ} \mathrm{C}$, the body temperature gradually rises and causes collapse. A victim exposed for more than a few minutes in high temperature exceeding $120^{\circ} \mathrm{C}$ may die immediately after exposure owing to hyperthermia, severe cardiac irregularities, or burns of the upper respiratory tract [12]. Of course, during the evacuation, victims may be directly exposed to the fire for the period of time, and to thermal radiation which may be more critical than the air temperature, and pathological effects will be dominant.

\section{2) Thermal effects}

Thermal radiation is defined as "a hazard because of heating effect which can be sufficient to burn the skin, or ignite combustible materials such as clothing [10]". The effect usually depends on time exposure, i.e. how extensively burned the person is. The severity of an injury from heat is determined by the depth of the skin. The thermal radiation required to produce a given level of fatality is commonly defined in thermal dose unit (TDU). Dose is calculated using the following formula: Dose $=I^{4 / 3} \times t$, where $I$ is the incident thermal flux $\left(\mathrm{kW} / \mathrm{m}^{2}\right)$, and $t$ is the exposure time (seconds). Thus, TDU is Thermal dose $=1\left(\mathrm{~kW} / \mathrm{m}^{2}\right)^{4 / 3} \times s$.

We quote the range of thermal doses required to give various levels of injuries [10], as seen in Table II, although discrepancies exist in the literature concerning the interval of 
the thermal doses that lead into pain, injury and fatality due to the difficulty in determining exact severity. An individual suffering either from pain or first degree burns from a thermal dose received, can still escape rapidly. The injury should not be sufficient to impede movement. An individual with second degree burns will experience greater motivation to escape, commonly referred to as the fight or flight response [10]. However, the pain from the injury may impede people from doing simple tasks such as turning door handles or dressing in survival equipment. Individuals with third degree burns will be in severe pain and will probably incur further injury as skin may fall away from the wound. They are considered as casualties who cannot evacuate unassisted.

TABLE II: RANGE OF THERMAL DOSES AND FATAL OUTCOME

\begin{tabular}{lll}
\hline \hline Effect & Depth of Burn & $\begin{array}{l}\text { Thermal Dose } \\
\left(s^{*}\left[\mathrm{~kW} / \mathrm{m}^{2}\right]^{4 / 3}\right)\end{array}$ \\
\hline Pain and Significant Injury & $<0.12 \mathrm{~mm}$ & $86-103$ \\
First Degree Burn & $>0.12-<2 \mathrm{~mm}$ & $80-130$ \\
Second Degree Burn & $>2 \mathrm{~mm}$ & $870-350$ \\
Third Degree Burn &
\end{tabular}

To assess the severity of thermal radiation, probit is normally used. Probit is the percentage of a defined population which will suffer a defined level of harm (normally death) when it is exposed to a specified dangerous load. The form of the probit equation is: $\operatorname{Pr}=a+b \operatorname{Ln}\left(I^{n} \times t\right)$, where $\operatorname{Pr}$ is the probit (or the probability measure), $a, b$ and $n$ are constants. $I$ is the radiation intensity given in $\mathrm{kW} / \mathrm{m}^{2}$ and $t$ is the exposure time in seconds [11]. The fatality rates from different thermal doses and exposure time, using the following probit function Probit=-12.8+2.56( $\left.I^{4 / 3 \times t}\right)$ is shown in Table III.

TABLE III: TNO PROBIT MODEL (NAKED HuMAN SKIN): FATALITY RATE AS A FUNCTION OF THERMAL RADIATION AND EXPOSURE TIME

\begin{tabular}{c|ccc}
\hline \hline \multirow{2}{*}{$\begin{array}{c}\text { Exposure } \\
\text { (seconds) }\end{array}$} & \multicolumn{3}{|c}{ Fatality rate $(\%)$} \\
\cline { 2 - 4 } & $10 \mathrm{~kW} / \mathrm{m}^{2}$ & $20 \mathrm{~kW} / \mathrm{m}^{2}$ & $30 \mathrm{~kW} / \mathrm{m}^{2}$ \\
\hline 10 & 0 & 5 & 39 \\
20 & 1 & 53 & 93 \\
30 & 11 & 87 & 100 \\
40 & 31 & 97 & 100 \\
50 & 53 & 99 & 100 \\
60 & 71 & 100 & 100 \\
\hline \hline
\end{tabular}

Certainly, there are other factors affecting the fatality and capability of occupants to escape from the accident venue, such as the effect of the protective measures, e.g. clothes and smoke masks. The majority data for the human response in fire referred to in this paper are given for lightly clothed people.

\section{3) Smoke effects}

The hazard of smoke is characterized by three factors: reduced visibility due to soot, the hot smoke that causes pain and injuries, irritating components, and the concentration of toxic gas that can lead into incapacitation. The smoke effects will be divided into two, i.e. smoke obscuration and smoke inhalation.

TABLE IV: SMOKE DENSITY AND VISIBILITY [4]

\begin{tabular}{l|r|r}
\multicolumn{2}{c}{ TABLE IV: SMOKE DENSITY AND VISIBILITY [4] } \\
\hline \hline $\begin{array}{l}\text { Degree of familiarity } \\
\text { with inside building }\end{array}$ & $\begin{array}{c}\text { Smoke Density } \\
\text { (extinction coefficient) }\end{array}$ & Visibility \\
\hline Unfamiliar & $0.151 / \mathrm{m}$ & $13 \mathrm{~m}$ \\
Familiar & $0.51 / \mathrm{m}$ & $4 \mathrm{~m}$ \\
\hline \hline
\end{tabular}

Smoke obscuration is a visibility effect, i.e. the maximum distance at which an object of defined size can be recognized, which is usually EXIT signs. Visibility depends on the obscuration along the line of sight. Reduced visibility through smoke is caused by two reasons: first, luminous fluxes from a sign and its background are interrupted by smoke particles and reduced in intensity before reaching the eyes of the victim. Second, luminous flux scattered from the general lighting of corridors or room by smoke particles in the direction of the victim's eyes. The walking speed of the victim decreases as smoke density becomes thicker and they find it difficult to walk forward [4]. The allowable smoke densities and visibility that permits safe escape can be seen in Table IV.

Smoke inhalation is a result of exposure from hot and asphyxiant gases produced during the fire. Loss of consciousness caused by the combined effects of carbon monoxide, hydrogen cyanide with additional effects from decreased oxygen content, increased carbon dioxide content in the blood and inhaled irritants are main reasons for incapacitation. Loss of consciousness prevents victims from escaping, leads to further uptake of asphyxiants, and is likely to result in death within some minutes, unless the victims are rescued [13]. Toxicity is usually measured by Toxic dose, which defined as $C^{n} \times t$, where $C$ is the concentration in ppm, $t$ is the exposure time in minutes and $n$ is a constant. Table $\mathrm{V}$ and Table VI respectively show the effect of Carbon monoxide exposure and Carbon dioxide on humans.

TABLE V: EFFECT OF CARBON MONOXIDE EXPOSURE

\begin{tabular}{|c|c|}
\hline CO Level & Effects \\
\hline $1500 \mathrm{ppm}$ & Headache after $15 \mathrm{~min}$, collapse after $30 \mathrm{~min}$, death after 1 hour \\
\hline $2000 \mathrm{ppm}$ & Headache after $10 \mathrm{~min}$, collapse after $20 \mathrm{~min}$, death after $45 \mathrm{~min}$ \\
\hline $3000 \mathrm{ppm}$ & $\begin{array}{l}\text { Maximum "safe" exposure for } 5 \mathrm{~min} \text {, danger of collapse in } 10 \\
\text { min, danger of death in } 15 \text { to } 45 \mathrm{~min}\end{array}$ \\
\hline $6000 \mathrm{ppm}$ & \multirow{3}{*}{$\begin{array}{l}\text { Headache and dizziness in 1-2 min, danger of death in } 10-15 \mathrm{~min} \\
\text { Immediate effect, unconscious after } 2-3 \mathrm{~min} \text {, danger of death in } \\
1-3 \mathrm{~min}\end{array}$} \\
\hline 12800 & \\
\hline ppm & \\
\hline \multicolumn{2}{|r|}{ TABLE VI: EFFECT OF CARBON DIOXIDE EXPOSURE } \\
\hline $\begin{array}{l}\mathrm{CO}_{2} \text { Level } \\
\text { in }(000 \mathrm{ppm})\end{array}$ & Effects \\
\hline $45 \mathrm{ppm} / 4.5 \%$ & $\begin{array}{l}\text { Reduced concentration capability for more than } 8 \text { hours } \\
\text { exposure, adaptation possible }\end{array}$ \\
\hline $55 \mathrm{ppm} / 5.5 \%$ & $\begin{array}{l}\text { Breathing difficulty, headache and increased heart rate } \\
\text { after } 1 \text { hour }\end{array}$ \\
\hline $65 \mathrm{ppm} / 6.5 \%$ & Dizziness, and confusion after 15 minutes exposure \\
\hline $70 \mathrm{ppm} / 7.0 \%$ & $\begin{array}{l}\text { Anxiety caused by breathing difficulty, becoming severe } \\
\text { after } 6 \text { min exposure }\end{array}$ \\
\hline $100 \mathrm{ppm} / 10 \%$ & Approaches threshold of unconsciousness in 30 minutes \\
\hline $120 \mathrm{ppm} / 12 \%$ & Limit of unconsciousness reached in $5 \mathrm{~min}$ \\
\hline $150 \mathrm{ppm} / 15 \%$ & Exposure limit 1 minutes \\
\hline $200 \mathrm{ppm} / 20 \%$ & Unconsciousness occurs in less than $1 \mathrm{~min}$ \\
\hline
\end{tabular}

There are plenty of hazardous gases that are not included in the description, depending also on the burned material. The two exposures considered in the Tables VI and VII are the effects that are almost certain to occur in the fire hazard.

TABLE VII: SURVIVABILITY CRITERIA

\begin{tabular}{l|l|l}
\hline \hline \multirow{2}{*}{ The Effects } & \multicolumn{2}{|c}{ Survivability Criteria } \\
\cline { 2 - 3 } & Short term exposure & Long term exposure \\
\hline $\begin{array}{l}\text { Thermal Radiation } \\
\left(\mathrm{kW} / \mathrm{m}^{2}\right)\end{array}$ & $\begin{array}{l}4.0(<3 \mathrm{~min}) \\
6.0(\mathrm{max})(1.5 \mathrm{~min})\end{array}$ & $\begin{array}{l}1.6(10 \mathrm{~min}) \\
(\text { no heavy clothing })\end{array}$ \\
\hline $\begin{array}{l}\text { Air temperature } \\
\left({ }^{\circ} \mathrm{C}\right)\end{array}$ & $140(5 \mathrm{~min})$ & $75-80(60 \mathrm{~min})$ \\
\hline $\begin{array}{l}\text { Carbon dioxide } \\
(\mathrm{ppm})(2)\end{array}$ & $30,000(3 \%)(15 \mathrm{~min})$ & $\begin{array}{l}20,000(2.0 \%) \\
(30 \mathrm{~min})\end{array}$ \\
\hline $\begin{array}{l}\text { Carbon monoxide } \\
(\mathrm{ppm})\end{array}$ & $1000(5 \mathrm{~min})$ & $500(30 \mathrm{~min})$ \\
\hline $\begin{array}{l}\text { Smoke obscuration } \\
\text { visibility }(\mathrm{m})\end{array}$ & $\begin{array}{l}3 \mathrm{~m} \\
(\mathrm{primary})(\text { compartment })\end{array}$ & $10 \mathrm{~m}$ (escape route) \\
\hline \hline
\end{tabular}


The authors are aware of different suggested thresholds in selected studies that can lead to incapacitation [10], [14], depending upon the nature of their experiments, the data, and the probit function being used in the calculation. The description in this section is rather intended for providing a basis to consider when developing our probabilistic model, particularly when discretizing the critical values and probability values and fatality assessment, and reference for survivability criteria as shown in Table VII.

\section{PROBABILISTIC APPROACH: BAYESIAN NETWORK}

Bayesian Network (BN) is a set of variables and a set of directed edges between variables that has a finite set of mutually exclusive states[15]. The variables together with the directed edges form a directed acyclic graph (DAG)". BN allows us to reason and represent an uncertain domain. The basis of BN is Bayes' Theorem as expressed below:

$$
p(A \mid B)=\frac{p(B \mid A) \cdot p(A)}{p(B)}
$$

where $p(A \mid B)$ is the posterior probability of the hypothesis $A$, given the data $B ; p(B \mid A)$ is the probability of the data $B$, given the hypothesis $A ; p(A)$ is the prior probability of the hypothesis $A$; while $p(B)$ is the prior probability of the data $B$, or the evidence. A probabilistic model may consist of a set of variables $X=\left(X_{1}, \ldots, X_{n}\right)$. In a $\mathrm{BN}$, the joint probability distribution will be:

$$
P\left(X_{1}, \ldots, X_{n}\right)=\prod_{i=1}^{n} p\left(X_{i} \mid p a_{i}\right)
$$

The joint probability distribution contains a table of values that captures the probability information of every possible combination of a set of variables, and their states. The BN model building is started with a network structure development, and determination of the nodes and probabilistic relations. The Conditional Probability Table (CPT) is then formulated, which defines the conditional probability distribution (CPD) of the variables.

Next, we can implement inference process or probability propagation which is triggered by a "flow of information" into the network. The posterior probability of one or more variables $X$ given a new evidence $e$ (new information about a random variable) or $p(X \mid e)$ can be calculated. It will propagate throughout the network and update the network's probability distribution. The procedure described in this section serve as basis for our BN model building and simulations in Section IV and V.

Our BN model also includes the diagnostic analysis, i.e. a process of finding the root cause of a system failure given a set of system observations such as symptoms, sensor readings, error codes, test results, historical findings. The technique is normally carried out to determine component failure or malfunction, given test results. The diagnostic model essentially captures how possible defects of a system can manifest themselves by error messages, symptoms, and test results [16]. In a diagnostic $\mathrm{BN}$ model, three types of variables are considered: First, faulty variables, i.e. variables representing the failures of the system or a specific part of the system. Second, variables which have an observable effect if the device is in some faulty state. It is performed when the faulty part is clear but the effects are obscured so that information about the state of the system unfolds in a testing. These observation or test variables are known as evidence variables. Third, variables which indicate context properties of the device that may influence the risk of causing a fault.

The models, reasoning and diagnosis described in this paper were created using the GeNIe modeling environment and SMILE library. The BN environment is developed by the Decision Systems Laboratory of the University of Pittsburgh [17].

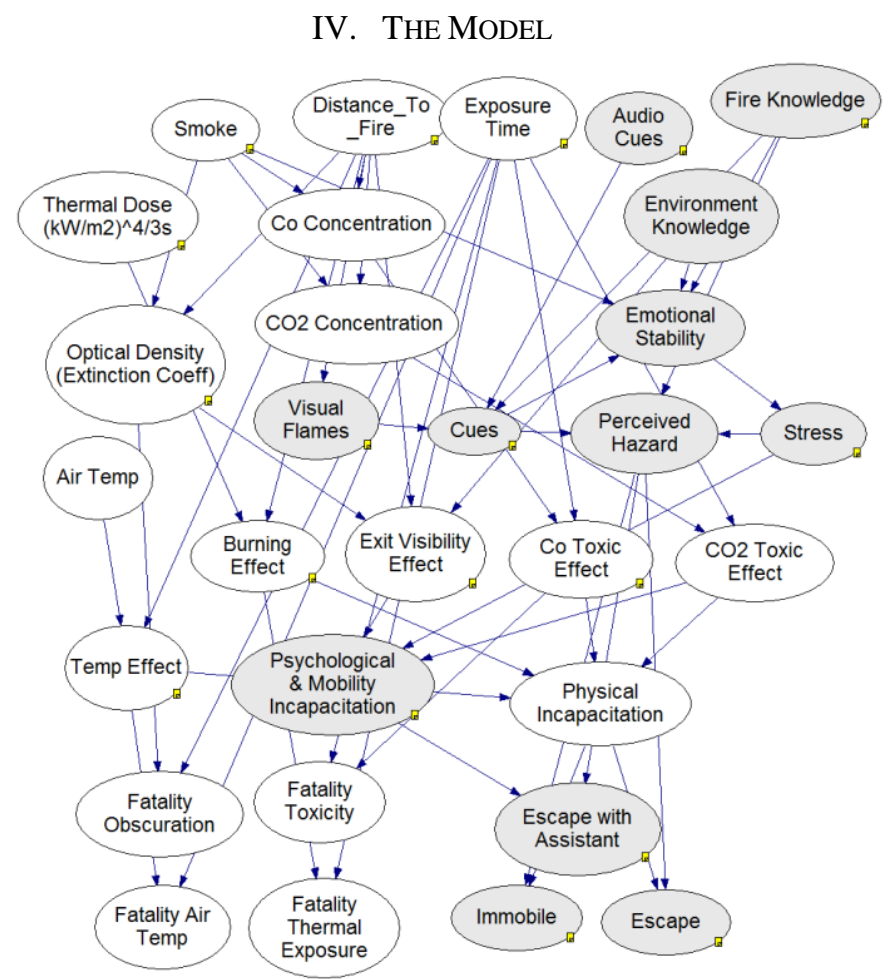

Fig. 1. BN model for diagnosing human health in fire.

Fig. 1 depicts the BN model that captures the intertwined interactions between human psychological and physiological response in fire. The grey nodes represent the human cognitive response against fire. The rest capture human physiological response. Therefore, the description of the model is divided into two sub-sections, to make it easier for readers to recognize the elements of the two tracks of literature being used in the model (Table VIII).

Some nodes contain continuous variables. For instance, "Exposure Time" can vary from $1,2,3, \ldots n$ minutes; or "Air Temperature" can be any values from $0{ }^{\circ} \mathrm{C}$ to $230{ }^{\circ} \mathrm{C}$. However, to make the $\mathrm{BN}$ work, we need to discretize continuous variables. Discretization is implemented such as to divide the states of "Thermal Dose" and Air Temperature into low, medium, and high, or to split "Exposure Time" into short, medium, and long. All nodes in the psychological part are discrete, such as "yes" and "no", or "true" and "false" values.

\section{Simulations AND Results}

We simulated the model to assess the human condition given different fire effects. Two scenarios were simulated: short and long term fire by putting evidence in selected nodes 
(Table IX). The evidence of the "Distance to Fire" node was also varied. We tested these scenarios against two possible passenger's knowledge about fire: if they are aware and unaware. Aware means that the passengers hear audio announcement, have fire knowledge and know environment layout (ship layout). All these variables were set to "true". By contrast with unaware, none of these three nodes are true.

TABLE VIII: DESCRIPTION OF NODES IN THE MODEL

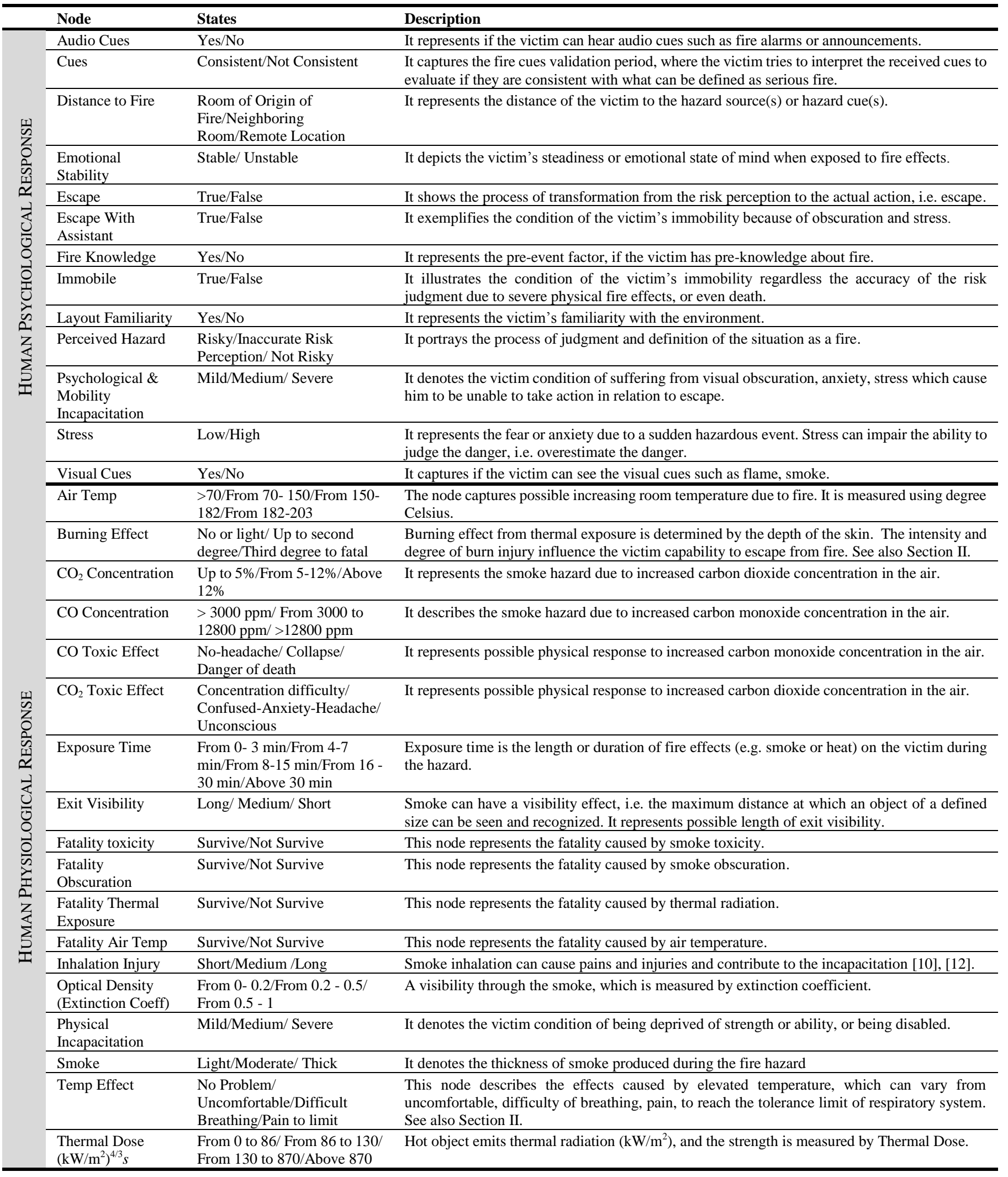

Tables X, XI and XII show the results of probability distributions of variables of interest, under scenarios defined earlier. Note that 1,2 and 3 in all the three tables indicate each state of the "Distance to Fire" node, i.e. "Room of origin of fire",
"Neighboring room" and "Remote location" respectively.

The results in Table $\mathrm{X}$ show no differences when varying the victim's awareness as true and false under the short term fire scenario. It means that both knowledge about fire or 
familiarity with the environment are not main factors affecting escape capability of the victims and survivability from potential fire effects. The reason for these comparable results is that the short exposure fire effects (4-7 minutes) in principle are not sufficient to incapacitate victims.

\begin{tabular}{l|l|l}
\multicolumn{3}{c}{ TABLE IX: SCENARIO AND EVIDENCE } \\
\hline \hline Node Name & Short Term & Long Term Fire \\
\hline \hline & State & State \\
\hline Air Temp & "From 70 to 149" & From 150 to 182 \\
Thermal Dose & From 0 to 86 & From 130 to 870 \\
Smoke & Light & Thick \\
Exposure Time & $4-7$ min & $8-15$ min \\
\hline
\end{tabular}

TABLE X: THE PROBABILITY DistribUtions OF SHORT TERM FiRE SCENARIO, WITH AND WITHOUT AWARENESS

\begin{tabular}{l|l|r|r|r}
\hline \multirow{2}{*}{ Nodes } & \multirow{2}{*}{ States } & \multicolumn{3}{c}{ Distance to Fire } \\
\cline { 2 - 5 } & & 1 & 2 & 3 \\
\hline \hline Fatality & Survive & 1 & 1 & 1 \\
Thermal & Not Survive & 0 & 0 & 0 \\
\hline Fatality Air & Survive & 1 & 1 & 1 \\
Temperature & Not Survive & 0 & 0 & 0 \\
\hline Fatality & Survive & 1 & 1 & 1 \\
Obscuration & Not Survive & 0 & 0 & 0 \\
\hline Fatality & Survive & 1 & 1 & 1 \\
Toxicity & Not Survive & 0 & 0 & 0 \\
\hline \hline Escape & True & 1 & 1 & 1 \\
& False & 0 & 0 & 0 \\
\hline
\end{tabular}

Table XI presents the simulation results of the long term fire scenario which yields a thick layer of smoke, increases the air temperature and thermal radiation. The passengers are assumed to be familiar with the environment, and are aware of fire. Table XII is a result from the simulation using the same assumptions, except that the passengers are unfamiliar with the surrounding area, and don't notice the fire cues.

TABLE XI: LONG TERM FIRE SCENARIO, WITH AWARENESS

\begin{tabular}{l|l|r|r|r}
\hline \multirow{2}{*}{ Nodes } & \multirow{2}{*}{ States } & \multicolumn{3}{c}{ Distance to Fire } \\
\cline { 2 - 5 } & & 1 & 2 & 3 \\
\hline \hline Fatality & Survive & 0 & 0 & 0.80 \\
Thermal & Not Survive & 1 & 1 & 0.20 \\
\hline Fatality Air & Survive & 0 & 0 & 0.30 \\
Temperature & Not Survive & 1 & 1 & 0.70 \\
\hline Fatality & Survive & 0 & 0.25 & 0.75 \\
Obscuration & Not Survive & 1 & 0.75 & 0.25 \\
\hline Fatality & Survive & 0 & 0.30 & 0.40 \\
Toxicity & Not Survive & 1 & 0.70 & 0.60 \\
\hline \hline Escape & True & 0 & 0.2 & 0.11 \\
& False & 1 & 0.98 & 0.89 \\
\hline
\end{tabular}

TABLE XII: LONG TERM FIRE SCENARIO, WITHOUT AWARENESS

\begin{tabular}{l|l|r|r|r}
\hline \multirow{2}{*}{ Nodes } & \multirow{2}{*}{ States } & \multicolumn{3}{c}{ Distance to Fire } \\
\cline { 2 - 5 } & & 1 & 2 & 3 \\
\hline \hline Fatality & Survive & 0 & 0 & 0.80 \\
Thermal & Not Survive & 1 & 1 & 0.20 \\
\hline Fatality Air & Survive & 0 & 0 & 0.30 \\
Temperature & Not Survive & 1 & 1 & 0.70 \\
\hline Fatality & Survive & 0 & 0.25 & 0.75 \\
Obscuration & Not Survive & 1 & 0.75 & 0.25 \\
\hline Fatality & Survive & 0 & 0.30 & 0.40 \\
Toxicity & Not Survive & 1 & 0.70 & 0.60 \\
\hline \hline Escape & True & 0 & 0.1 & 0.60 \\
& False & 1 & 0.99 & 0.94 \\
\hline
\end{tabular}

The results show that awareness does not improve someone's capability to escape from a fire disaster when he/she occupies the affected room, and is exposed to the lethal fire effects in quite long time. But there exists a small chance for victims in neighboring rooms or remote distance to escape from affected areas. Further, well-informed people are less likely to have stress than those who are negligent. Yet, despite being emotionally more stable, the escape chance is not so high due to, particularly, the strong thermal effects which in theory can lead to incapacitation faster than other fire effects.

It is worth to mention that the fatality effects remain the same in Tables XI and XII, because we did not modify the evidence in the nodes in "Air Temp", "Thermal Dose" and "Smoke" when vary the "Distance to Fire" node.

Besides, we diagnosed factors that were likely to contribute to fatalities identified earlier, using the diagnosis feature in GeNie [17]. We used the "target type diagnostic" to find the faulty components of variables of interests, ranking the likely factors that led into incapacitation. The procedure was to select the target states to diagnose and to be ranked according to the probability they represent. We focus the diagnostic of victims in two locations: neighboring and remote locations. All are used to analyze the "Escape" node. We use the default Entropy/Cost Ratio, i.e. 1.95, and maximum 10.

\begin{tabular}{|c|c|}
\hline Ranked Targets & Probability \\
\hline Psychological \& Mobility Incapacitation:Severe & 1.00 \\
\hline Exit Visibility EffectShort & 1.00 \\
\hline Physical Incapacitation:Severe & 0.93 \\
\hline Emotional Stability: Unstable & 0.80 \\
\hline Perceived Hazard:Risky & 0.71 \\
\hline Temp Effect:Painlnjury & 0.55 \\
\hline Burning Effect:ThirdDegreeToFatal & 0.50 \\
\hline CO2 Toxic Effect:Confused_Anxiety_Headache & 0.50 \\
\hline Optical Density (Extinction Coeff):From_05_to_1 & 0.50 \\
\hline Visual Flames:Yes & 0.50 \\
\hline Cues & 0.41 \\
\hline Temp Effect:Difficult_Breathing & 0.40 \\
\hline Perceived Hazard:InaccurateRiskPerc & 0.21 \\
\hline Co Toxic Effect:Danger_of_Death & 0.20 \\
\hline CO2 Toxic Effect Unconscious & 0.20 \\
\hline Temp EffectRespiratoryTolerance & 0.05 \\
\hline Physical Incapacitation:Mild & 0 \\
\hline Psychological \& Mobility Incapacitation:Mild & 0 \\
\hline
\end{tabular}

Fig. 2. Ranked node targets: the passengers occupy neighboring room, without "awareness" assumptions.

Ranked Targets
Physical Incapacitation:Severe
Psychological \& Mobility Incapacitation:Severe
Cues
Perceived Hazard:Risky
Temp Effect:Painlnjury
Burning Effect:ThirdDegreeToFatal
CO2 Toxic Effect:Confused_Anxiety_Headache
Emotional Stability:Unstable
Exit Visibility EffectShort
Optical Density (Extinction Coeff):From_05_to_1
Visual Flames:Yes
Temp Effect:Difficult_Breathing
CO2 Toxic Effect:Unconscious
Co Toxic Effect:Danger_of_Death
Psychological \& Mobility Incapacitation:Mild
Perceived Hazard:InaccurateRiskPerc
Temp Effect:RespiratoryTolerance
Physical Incapacitation:Mild

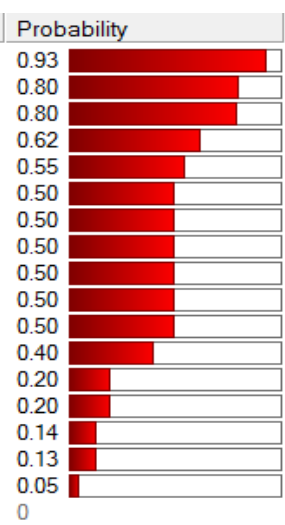

Fig. 3. Ranked node targets: the passengers occupy neighboring room, without "awareness" assumptions.

In Table XI and XII, the escape probabilities of victims located in neighboring rooms whether or not they are aware of the danger, are very close, i.e. 0.2 and 0.1 respectively. Although the results are pretty similar, the reasons for incapacitation stem from two slightly different mechanisms, as seen in Fig. 2 and 3. In Fig. 2, severe mobility incapacitation and psychological condition, short visibility, severe physical incapacitation, and unstable emotion are the four most likely causes of inability to escape. The first two nodes are indisputable, i.e. the probability is 1 . On the contrary, psychological effects are not a dominant factor 
affecting people located in remote location. Mostly, it is lethal effects that lead them into severe physical incapacitation (Fig. 3).

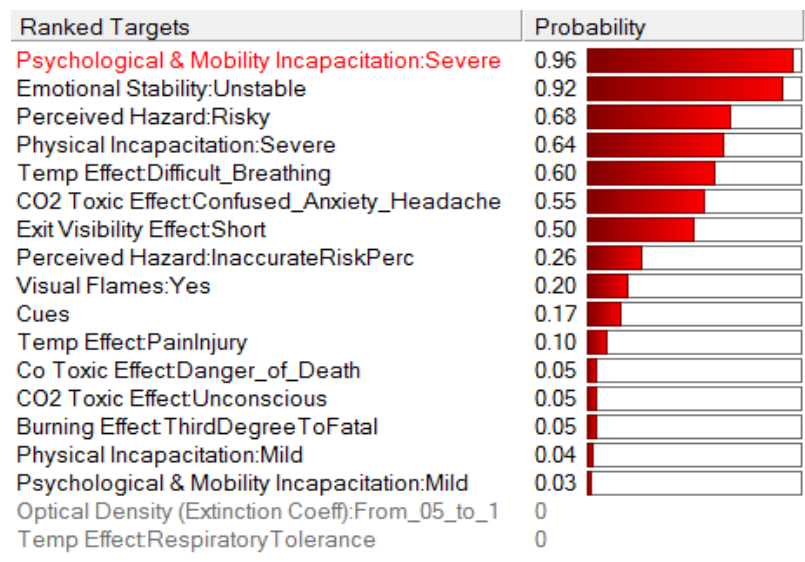

Fig. 4. Ranked node targets: the passengers are in remote location-without awareness assumptions.

\begin{tabular}{l|l|l|l|} 
Ranked Targets & Probability \\
\hline Cues & 0.68 & & \\
Physical Incapacitation:Severe & 0.64 & & \\
Perceived Hazard:Risky & 0.61 & & \\
Temp Effect:Difficult_Breathing & 0.60 & & \\
CO2 Toxic Effect:Confused_Anxiety_Headac... & 0.55 & & \\
Psychological \& Mobility Incapacitation:Seve... & 0.53 & & \\
Emotional Stability:Unstable & 0.50 & & \\
Psychological \& Mobility Incapacitation:Mild & 0.34 & & \\
Visual Flames:Yes & 0.20 & \\
Perceived Hazard:InaccurateRiskPerc & 0.15 & \\
Temp Effect:Painlnjury & 0.10 & \\
Co Toxic EffectDanger_of_Death & 0.05 & \\
CO2 Toxic Effect:Unconscious & 0.05 & & \\
Burning Effect:ThirdDegreeToFatal & 0.05 & & \\
Physical Incapacitation:Mild & 0.04 & \\
Exit Visibility EffectShort & 0 & \\
Optical Density (Extinction Coeff):From_05_to... & 0 & \\
Temp Effect:RespiratoryTolerance & 0
\end{tabular}

Fig. 5. Ranked node targets: the passengers are in remote location-with awareness assumptions.

Similarly, in Fig. 4 and Fig. 5 we illustrate the components that go wrong during the hazard in a remote location. Severe psychological/mobility incapacitation and unstable emotion are apparently influencing people located in a distance from the affected area, before finally all lethal effect works (Fig. 4). They can also be severely suffered from fire effects, in spite of being familiar with the environment, but merely because of not noticing the cues (Fig. 5).

\section{CONCLUSION}

We have described an intertwined psychological and physiological probabilistic model of a fire disaster. All fire effects that influence the ability of victims to escape are incorporated. While we have a solid literature base for building this model, the model's confidence can be enhanced through expert opinions. Yet, the usefulness of this way of thinking for the real-world application need further study.

In the long run, we want to include "human centric sensing" and "mobile sensing" paradigms in the research. Combination of sensing and intelligent systems are expected to turn this probabilistic thinking into a decision support for crises managers so that they can efficiently prioritize the most critical spots for rescue operations.

\section{REFERENCES}

[1] W. F. S. Center, "World fire statistics bulletin," in Fire as Vulnerability: The Value Added from Adopting a Vulnerability Approach, B. Woodrow, Ed. Geneva: Valéria Pacella, 2012, vol. 28.

[2] J. Švetak, "Analysis of the causes of maritime casualties," PROMET-Traffic\&Transportation, vol. 15, pp. 43-48, 2012.

[3] J. U. Schröder-Hinrichs, E. Hollnagel and M. Baldauf, "From Titanic to Costa Concordia - a century of lessons not learned," WMU Journal of Maritime Affairs, pp. 1-17, 2012.

[4] T. Jin, "Visibility and human behavior in fire smoke," in The SFPE Handbook of Fire Protection Engineering, M. A. Quincy, Ed. Massachussets: National fire Protection Association, 2008.

[5] E. D. Kuligowski, "Process of human behavior in fires," The National Institute of Standards and Technology (NIST), 2009.

[6] M. Kobes, I. Helsloot, B. de Vries, and J. G. Post, "Building safety and human behaviour in fire: A literature review," Fire Safety Journal, vol. 45, pp. 1-11, 2010.

[7] J. L. Bryan, "Behavioral Response to Fire and Smoke," in The SFPE Handbook of Fire Protection Engineering, M. A. Quincy, Ed. Massachussets: National fire Protection Association, 2008.

[8] G. Proulx, "Evacuation time," in The SFPE Handbook of Fire Protection Engineering, M. A. Quincy, Ed. Massachussets: National fire Protection Association, 2008.

[9] J. Drury, C. Cocking, and S. Reicher, "Everyone for themselves? A comparative study of crowd solidarity among emergency survivors," $\mathrm{Br}$. J. Soc. Psychol., vol. 48, pp. 487-506, September 2009.

[10] S. O'Sullivan and S. Jagger, Human Vulnerability to Thermal Radiation Offshore, Sheffield: Health and Safety Laboratory, 2004.

[11] OGP, Vulnerability of humans, International Association of Oil and Gas Producers, 2010.

[12] NFPA, The SFPE Handbook of Fire Protection Engineering, Quincy, Massachussets: National fire Protection Association, 2008.

[13] D. A. Purser, Assesment of Hazards to Occupant from Smoke, Toxic, Gases and Heat, M. A. Quincy, Ed. Massachussets: National fire Protection Association, 2008.

[14] J. F. S. Pérez, E. G. Ferradás, F. D. Alonso, D. P. García, M. V. M. Cano, and J. Á. B. Cotorruelo, "New probit equations for the calculation of thermal effects on humans," Process Safety and Environmental Protection, vol. 88, pp. 109-113, 2010.

[15] F. V. Jensen and T. D. Nielsen, Bayesian networks and decision graphs: Springer, 2007.

[16] P. Weber, G. Medina-Oliva, C. Simon, and B. Iung, "Overview on Bayesian networks applications for dependability, risk analysis and maintenance areas," Engineering Applications of Artificial Intelligence, vol. 25, pp. 671-682, 2012.

[17] D. S. Laboratory. (October 11, 2013). Guide to genie online help. [Online]. Available: http://www. genie.sis.pitt.edu

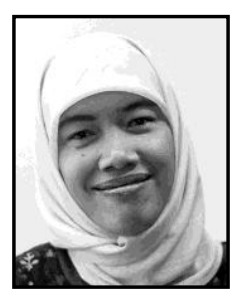

Jaziar Radianti is a researcher for CIEM (Centre for Integrated Emergency Management), University of Agder, Norway. Her research interests include crises management, system dynamics and Bayesian network modeling for crisis situations. She is also developing an interest toward research in mobile sensing and its intersections with human-centric computing and application for decision support in a crisis.

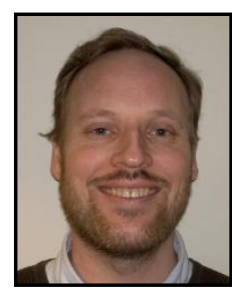

Ole-Christoffer Granmo is the deputy director for CIEM, who heads the Artificial Intelligence and its Industrial Applications Group and he is a Professor in ICT, University of Agder, Norway. His research interests include mobile devices, decentralized/distributed computing, human-centered sensing, data fusion, pattern recognition, planning \&resource allocation, GIS (for crisis mapping), and decision support. 